\title{
DESIGN AND FINITE ELEMENT ANALYSIS OF A CAR DOOR ON DIFFERENT SPEEDS \& DIFFERENT MATERIALS
}

\section{Dr. M. SHAMEER BASHA}

Professor, Department of Mechanical Engineering, Unayzah College of Engineering Qassim University, Qassim, Saudi Arabia

ABSTRACT
Automobile door is among the chief components that are used as security for passengers in unwanted accidents. The
most important objective of this work will be to create a suitable model of automobile door for Ford 250 automobile car to
perform a explicit dynamic structural analysis (strain and displacement evaluation) of automobile doorway by finite
element method to evaluate the operation of traditional, current and proposed substance. Finite evaluation is conducted
door for different levels by changing the substances and reduce the weight of the door using composite materials. By this
decrease the harm proportion of the automobile and passenger security. Within this paper the automobile doorway has
been modelled using parametric modelling computer software CATIA. Here is the norm in $3 D$ product design, including
industry-leading productivity resources which encourage best practices in style.
KEYWORDS: Ford 250 Car Door, FEA, CATIA \& ANSYS 15

Received: Jun 16, 2019; Accepted: Jul 06, 2019; Published: Oct 03, 2019; Paper Id.: IJMPERDDEC20196

\section{INTRODUCTION}

Automobile motives play an essential part in the transport of individuals both personal and in teams, in addition to goods. Large-scale manufacture of those cars, functioning of the transport (street ) system system, and building of the necessary infrastructure has notable effects on economic development of the nation. There is a significant demand for manufactured substances within this whole sector. Constant efforts are about creating newer or other substances to achieve cost effectiveness, fuel efficiency, low emissions, and greater security, and constantly with a goal on future capacity to market or bio degrade. But, the current rising cost of gas is an important element in the movement to use composites for many transportation vehicles, and therefore to accomplish a lightweight structure with the ultimate objective of decrease in gas consumption and emissions. Negative impacts are among those very poisonous accidents causing death and accidents annually around the term.

Doors are among the greatest elements in a vehicle which offer easy accessibility for passengers to the vehicle. With the expanding requirement for automobile styling, comfort, security and other systems integration (window ruler, mouse, speaker, engine and electronics) from the doorway, designing this method is a superb obstacle to engineers. Traditionally these components were designed, fabricated and secured individually. A doorway module is a meeting of practical components mounted on a carrier plate. Unlike traditional doorway methods, in which the window regulator gathering has been directly connected to the door interior panel, the doorway module consists of a carrier plate using window regulator gathering, glass speaker and motor. The window regulator is made up of motor assembly, a couple of rails to steer the glass movement, cursor or glass knobs to encourage both the glass, and mechanics to move up the glass and down. The window regulator speaker, along with other cable harnesses are mounted onto the carrier plate with bolts, rivets, along with also clips. 


\subsection{Car Door Panels}

Automobile doors are extremely important vehicle parts due to the fact that they let us easy access into the inside. Apart from this main purpose, doors will also be in charge of protecting us along with other passengers once we are on the street. Ultimately, these elements give your car or truck a fashionable appearance that definitely turns heads when you push down the street. To ensure the door becomes enough security, it ought to be outfitted with a trusted door.

Fundamentally, door panels have been mounted within the car door and are frequently coated in leather or vinyl. Some vehicles have door panels covered in cloth another material. The selection of cover material really is dependent upon the design of different elements from the automobile's interior such as the dash, carpeting, and chairs because a car door is usually supposed to rival the manner of the automobile's interior.

\subsection{Problem Definition}

To examine and design a mix door module for auto body use to accomplish a weight loss in comparison to present burden of metal door module. The current day cars utilize steel door modules to get doorway construction. Steel door modules are somewhat heavier, more expensive for building and need much more time during fabrication of doors because of nonintegration of elements.

\subsection{Methodology}

- "Design of door module was understood using literature, journals, books and other reference media.

- Surface model of existing front door assembly with steel door module plate was created using CATIA-v5-r17 using reverse engineering.

- Benchmark values for existing door assembly under durability loads were arrived by performing stress analysis using Altair Hyper Mesh, Ansys.

- The other method is to replace traditional materials, like mild steel, with lightweight materials, such as aluminium alloy, magnesium alloy and high strength steel, and composite. by these two methods, material replacement is generally more efficient in achieving a lightweight automobile than structural modification.

- In this paper the structural modification and impact absorption of material was investigated using different material simultaneously using finite element analysis and compared to best way to reduce structural weight without sacrificing safety is to employ composite material, due to is higher strength to weight ratio than that of conventional steel. Composite materials are widely used in aerospace industries".

\section{LITERATURE REVIEW}

Previous studies by different researches show that the efficient design and increase use of composite materials into the automotive parts directly influences the car safety, weight reduction and gas emission, because the efficient design can absorb more deformation and composite materials have high specific strength (strength to density) and high specific stiffness (stiffness/density). They also have very high impact load absorbing and damping properties.

The side impact door should have the ability to absorb as much deformational energy as possible without breaking. Steel is still the most widely used material for beam members, but the steel increases the total weight of the car. However, breakthroughs in the application of lighter materials, such as composite, are being initiated in the automotive 
industry. Correct fiber orientation and stacking sequence of the cross-ply laminate contribute to higher energy absorption when compared to steel equivalent.

"The composite materials are replacing most of the steel structures. Rotors manufactured using RTM (Resin Transfer Molding) for air compressor or super chargers of cars are used to substitute for metal rotors which are hard to manufacture [4]".

"The composite material was for the first time introduced to the formula-1 in 1980 by McLaren team. Since then the crashworthiness of the racing cars has improved beyond all recognition. They used the carbon fiber composite to manufacture the body, which is low weight, high rigidity and provided the high crash safety standards [11]".

"The lightweight composite materials are already finding the exciting break in the automotive field as a means to increase the fuel efficiency. The vehicle weight directly contributes about 75 percent of fuel consumption. The vehicle industry can anticipate an aggressive 6 to 8 percent reduction in fuel consumption with 10 percent decrease in vehicle weight. This reduces around 20 kilogram of carbon dioxide emission per kilogram reduction in weight over the vehicle's lifetime [5]".

"The report from the united states and Canada predicted that plastics and composites would be widely used applied to body panels, bumper systems, flexible components, trims, drive shaft and transport parts of cars. Also rotors manufactured using RTM (Resin Transfer Moldings) for air compressor or superchargers of cars have been used to substitute for metal rotors which are difficult to machine [4]. Composites have been used to substitute flexi spline materials in harmonic drives [7]".

"Previous studies by different researches show that the efficient design and increase use of composite materials into the automotive parts directly influences the car safety, weight reduction and gas emission, because the efficient design can absorb more deformation and composite materials have high specific strength (strength to density) and high specific stiffness (stiffness/density). They also have very high impact load absorbing and damping properties.

The composite materials have high specific energy absorption when compared to steel. The properties like high specific strength and high specific stiffness are attractive for the construction of lightweight and fuel efficient vehicle structures. The energy absorption capability of the composite materials offers a unique combination of reduced weight and improves crashworthiness of the vehicle structures. Fuel efficiency of the vehicle directly depends on the weight of the vehicle. The carbon fiber composite body structure is $57 \%$ lighter than steel structure of the same size and providing the superior crash protection, improved stiffness and favorable thermal and acoustic properties. The composite materials are replacing most of the steel structures. Rotors manufactured using RTM (Resin Transfer Molding) for air compressor or super chargers of cars are used to substitute for metal rotors which are hard to manufacture. The composite material was for the first time introduced to the formula-1 in 1980 by McLaren team. Since then the crashworthiness of the racing cars has improved beyond all recognition. They used the carbon fiber composite to manufacture the body, which is low weight, high rigidity and provided the high crash safety standards. The lightweight composite materials are already finding the exciting break in the automotive field as a means to increase the fuel efficiency. The vehicle weight directly contributes about 75 percent of fuel consumption. The vehicle industry can anticipate an aggressive 6 to 8 percent reduction in fuel consumption with 10 percent decrease in vehicle weight. This reduces around 20 kilogram of carbon dioxide emission per kilogram reduction in weight over the vehicle's lifetime. The report from the united states and Canada predicted that 
plastics and composites would be widely used applied to body panels, bumper systems, flexible components, trims, drive shaft and transport parts of cars. Also rotors manufactured using RTM (Resin Transfer Moldings) for air compressor or superchargers of cars have been used to substitute for metal rotors which are difficult to machine. Composites have been used to substitute flexi spline materials in harmonic drives".

\section{RESULTS \& DISCUSSIONS}

After the creation of the model using the design software, the geometric model is converted into STEP format in order to avoid data losses occurring due to importation of the geometric design file. There are three main steps involved in the analysis software, namely: pre-processing, solution and post processing. In the pre-processing stage, the geometric domain of the model is imported along with its material properties and boundary constraints. Further the geometric is meshed in several nodes and elements for accurate evaluation of the problem. In the solution phase, the governing algebraic equations are formed and the unknown values are evaluated. The computed results are again utilized by back substitution method to determine the other additional variables and required information. In the post processing phase, the analysed results are evaluated and displayed.

Finite Element Analysis of car door using ANSYS Workbench The model of the car door is meshed by using ANSYS WORKBENCH software. The car door is provided with necessary working loading which is considered to be uniformly distributed throughout the car door.

\subsection{Materials Properties}

\subsubsection{Aluminium Alloy}

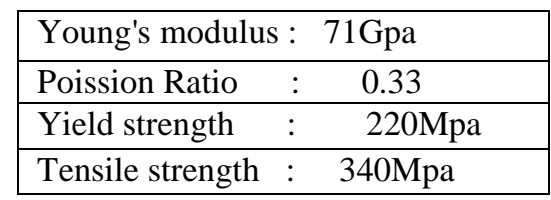

\subsubsection{E-Glass}

Table 1

\begin{tabular}{|l|l|l|c|c|}
\hline Young's Modulus & Shear Modulus & Poission Ratio & Tensile Strength & Compressive Strength \\
\hline E11 $=135.5 \mathrm{Gpa}$ & Gxy $=5.2 \mathrm{Gpa}$ & Nuxy $=0.24$ & $2050 \mathrm{Mpa}$ & $5000 \mathrm{Mpa}$ \\
\hline $\mathrm{E} 22=135.5 \mathrm{Gpa}$ & $\mathrm{Gyz}=3.08 \mathrm{Gpa}$ & Nuyz $=0.3$ & & \\
\hline E23 $=9 \mathrm{Gpa}$ & $\mathrm{Gzx}=3.08 \mathrm{Gpa}$ & Nuzx $=0.3$ & & \\
\hline
\end{tabular}

\subsection{Geometry Model}
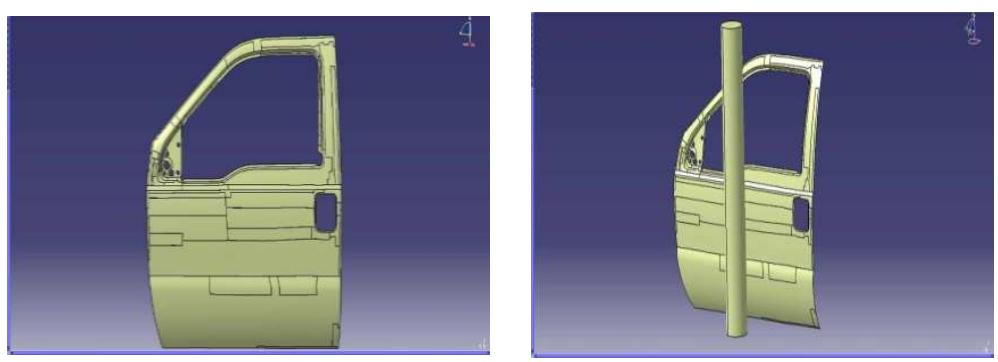

Figure 1: Geometry Model.

Ford 250 car door FE model is downloaded from internet source. Surfaces extracted from FE model and create the 3D model by using CATIA V5. 


\subsection{Meshing and Boundary Conditions}

"The figure. 2 shows the meshed model of door. The discretization (Mesh generation) is the first step of Finite Element Method. In this step the component or part is divided into number of small parts. In discretization the no of elements are 9095, and 7688 nodes. The effect of force on each portion of the component is not same. The purpose of discretization is to perform the analysis on each small division separately.

The figure 3, 4, 5 shows the study model of door. After the application of boundary conditions and force, the next step is to perform the impact analysis of door. In this impact analysis, we are mainly concern with the total deformation and the stresses acting on the door (von-masses stresses). When the force is applied, the slight deformation and also the stresses take place on the door. The total deformation of door is shown in figures $6,9,12,15$. The deformation in the door is not same throughout. The portion in red color shows that the deformation at that region is maximum and the portion in blue color shows that the deformation is minimum in that region. The von-miseses stresses of door is shown in figures 7 , $10,13,16$.

In this stageigs file is imported to the ansys workbench. The CAD data of the car door structure is imported and the surfaces were created and meshed.

Number of nodes: 19575

Number of elements: 16431

The two-dimensional model was meshed using a shell mesh was done. The meshing of the model was carried out using smart size mesh. After the meshing process has completed then the boundary conditions applied. These boundary conditions are the reference points for calculating the results of analysis".

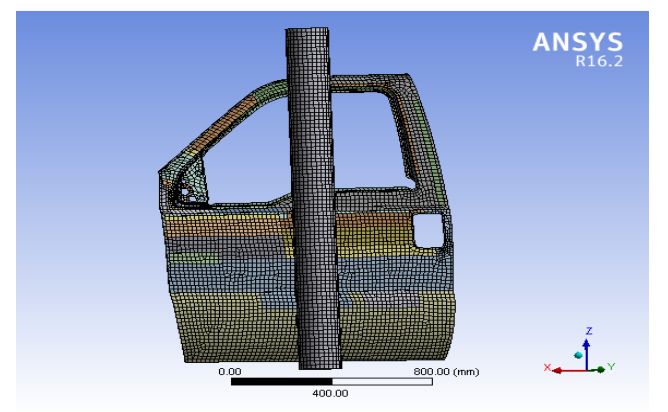

Figure 2: Mesh Model of Car Door.

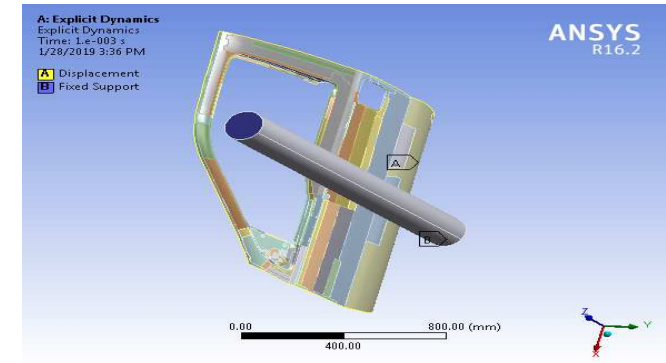

Figure 3: Boundary Condition.

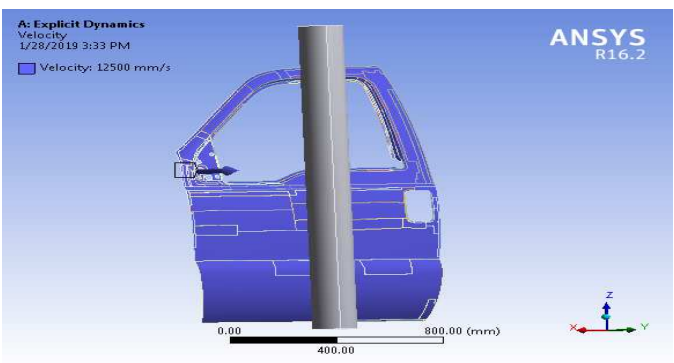

Figure 4: Velocity Boundary condition with 45kmph. 


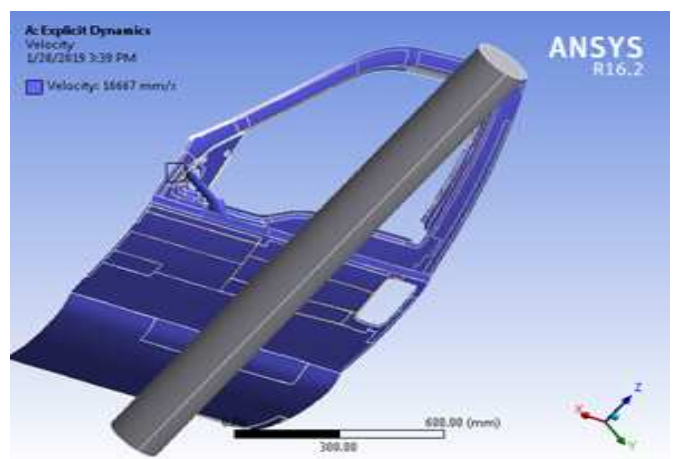

Figure 5: Velocity Boundary Condition with 60kmph.

\subsection{Impact Analysis of Car Door}

Two materials are considered for impact analysis of car door by changing the materials to check the stress, strain and deformation. Stresses, Strain and deformations are calculated for two materials.

Case 1: Analysis Results of Alluminium Alloy with Speed of 45kmph

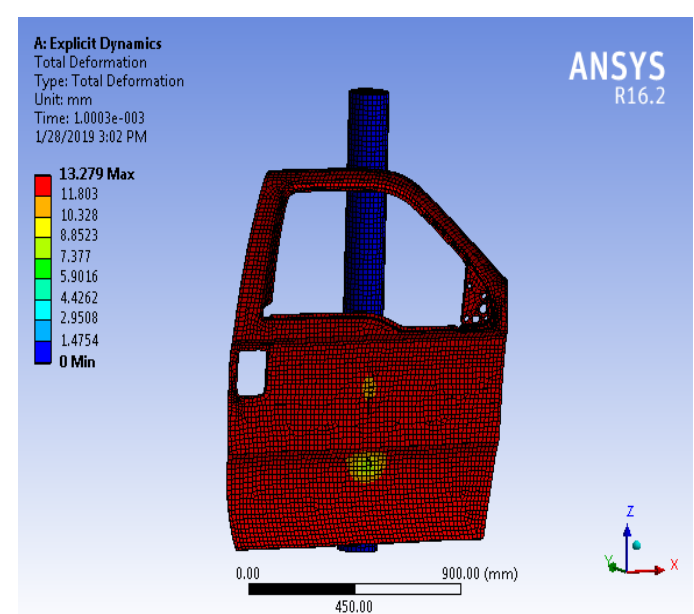

Figure 6: Deflection of Car Door with 45kmph Speed.

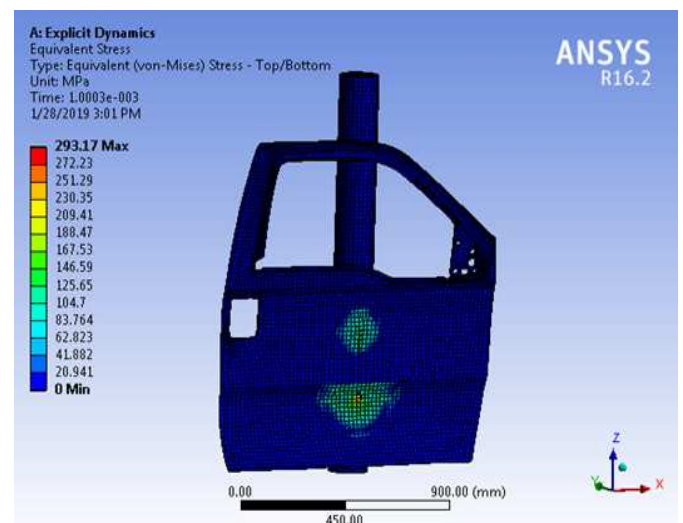

Figure 7: Von mises Stress of Car Door with 45kmph Speed.

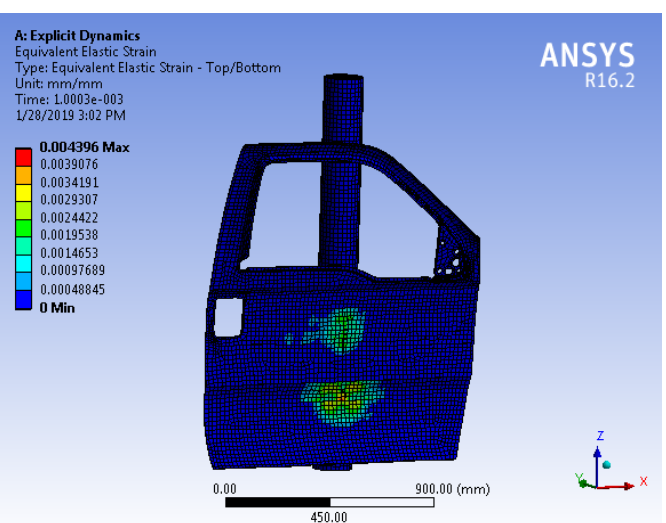

Figure 8: Strain of Car Door with 45kmph Speed. 
Case 2: Analysis Results of Alluminium Alloy with Speed of 60kmph

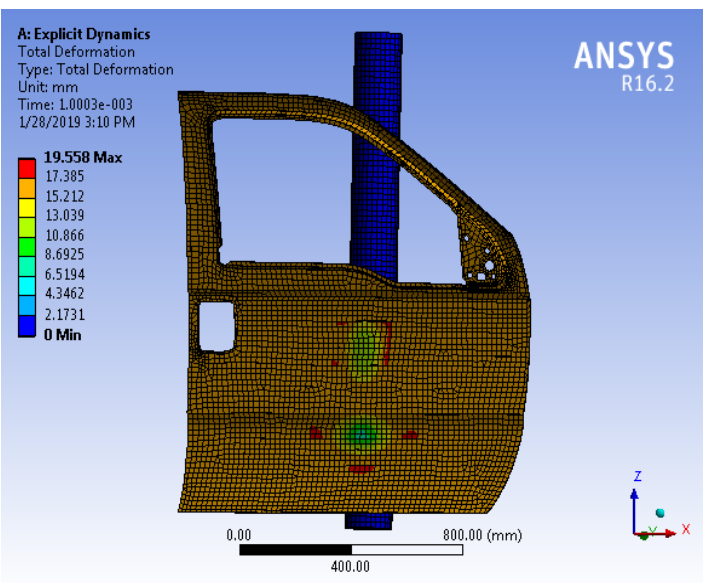

Figure 9: Deflection of Car Door with 60kmph Speed.

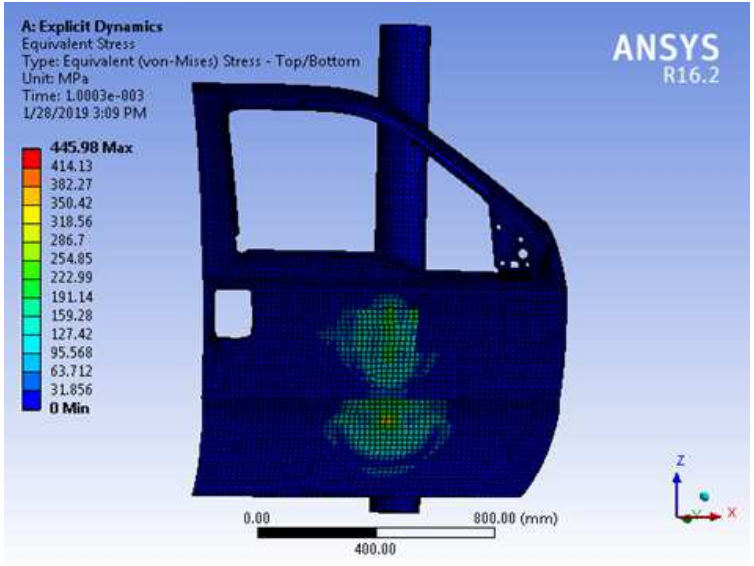

Figure 10: Von Mises Stress of Car Door with $60 \mathrm{kmph}$ Speed.

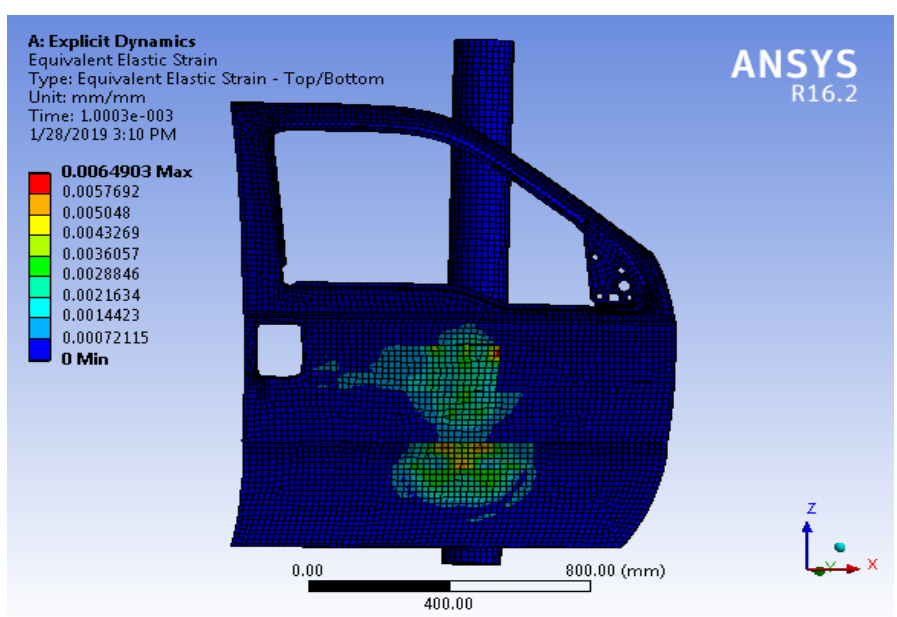

Figure 11: Strain of Car Door with 60kmph Speed.

Case 3: Analysis Results of E-Glass with Speed of $45 \mathrm{kmph}$

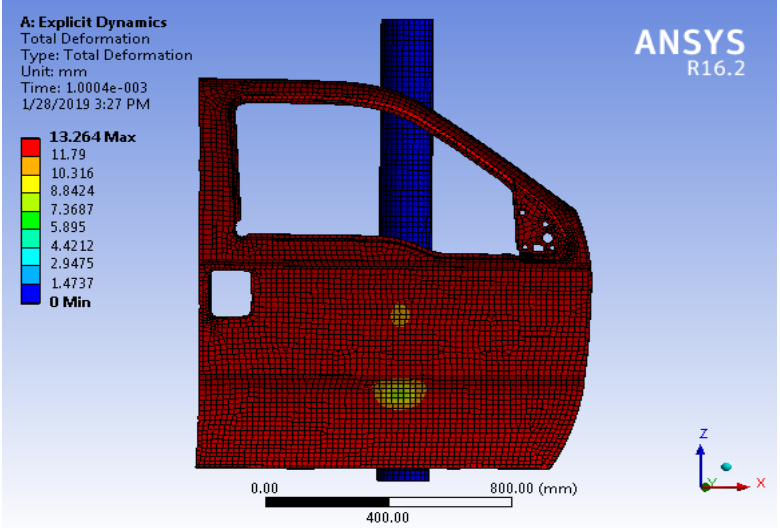

Figure 12: Deflection of Car Door with 45kmph Speed.

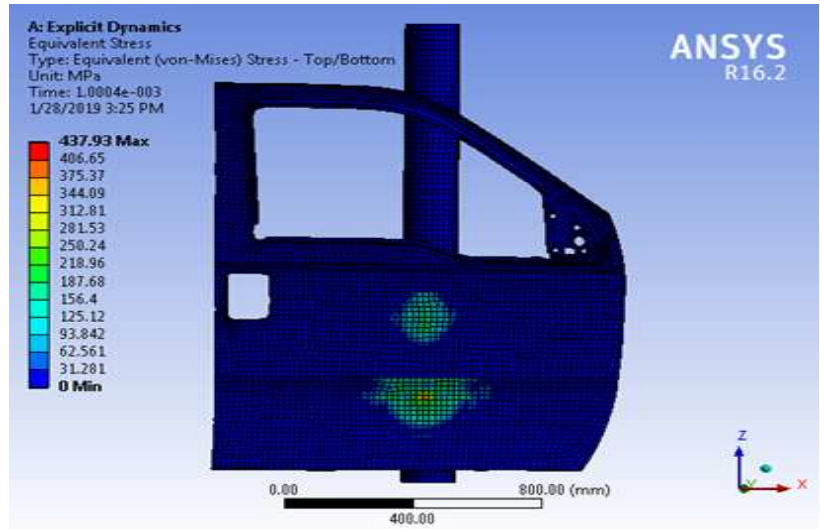

Figure 13: Von mises Stress of Car Door with 45kmph Speed. 


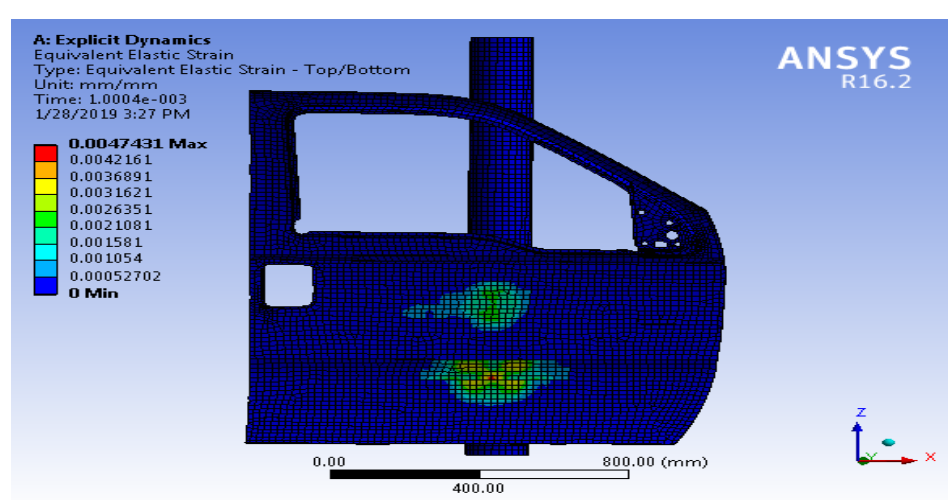

Figure 14: Strain of Car Door with 45kmph Speed.

Case 4: Analysis Results of E-Glass with Speed of 60kmph

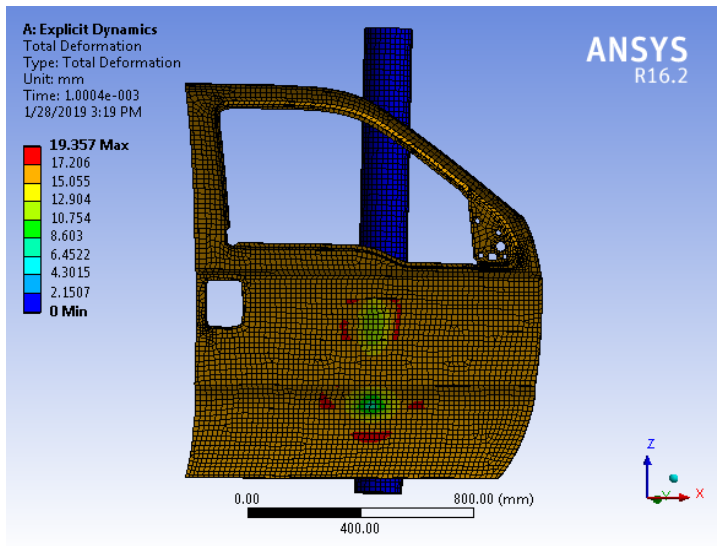

Figure 15: Deflection of Car Door with 60kmph Speed.

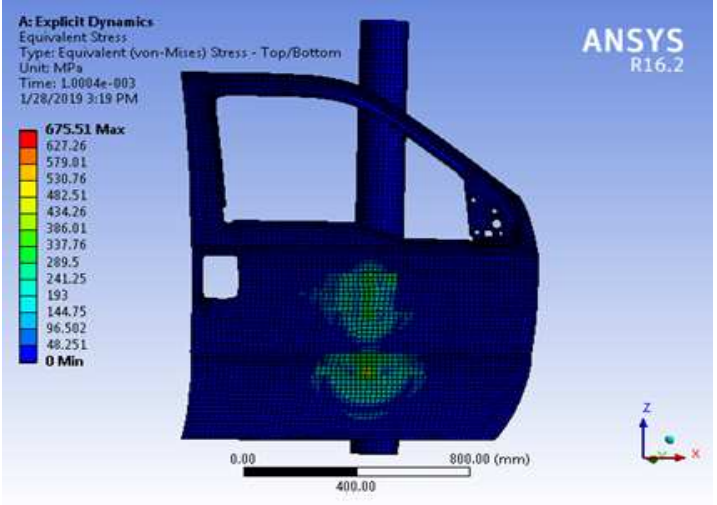

Figure 16: Von mises Stress of Car Door with 60kmph Speed.

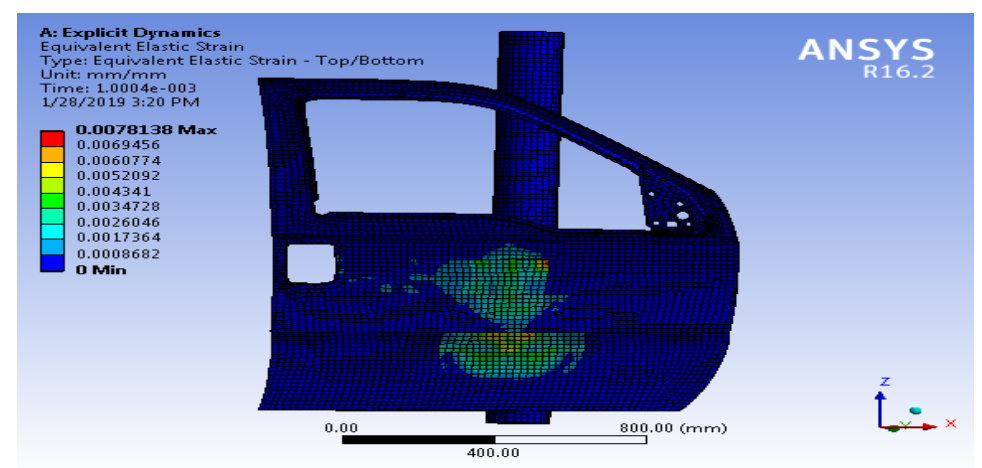

Figure 17: Strain of Car Door with 60kmph Speed.

Table 2: Results obtained for Alluminium Alloy

\begin{tabular}{|c|c|c|c|c|}
\hline Materials & Speed & Stress $\left(\mathbf{N} / \mathbf{m m}^{\mathbf{2}}\right)$ & Strain & Displacement \\
\hline Aluminium alloy & $45 \mathrm{kmph}$ & 293.17 & 0.0043 & 13.279 \\
\hline Aluminium alloy & $60 \mathrm{kmph}$ & 445.98 & 0.0064 & 19.55 \\
\hline
\end{tabular}

Table 3: Results Obtained for E-Glass

\begin{tabular}{|l|c|c|c|c|}
\hline Materials & Speed & Stress(N/mm2) & Strain & Displacement \\
\hline E-glass & $45 \mathrm{kmph}$ & 437.93 & 0.0047 & 13.264 \\
\hline E-glass & $60 \mathrm{kmph}$ & 675.57 & 0.0078 & 19.35 \\
\hline
\end{tabular}


By observing the analysis results, stresses, strains and deformations of Aluminum alloy and E-glass composite are compared. The stress, stain and deformation of composite material values are less than their respective yield stress value. So using composite material is safe under given loading conditions. Composite material stress, strain and deformation was less than that of Aluminium alloy.

\section{CONCLUSIONS}

Finite Element analysis of the impact of the car door has been done using FEA tool Ansys workbench. From the results obtained from FE analysis, many discussions have been made. In this paper, Aluminium and E-glass materials are used for side-door impact for passenger cars, was designed to reduce weight, as well as to improve impact energy absorption.

- Results show improvement in the strength of the door as the maximum limits of stresses. The values of von-mises stresses that comes out from the ansys workbench is far less than material yield stress so our design is safe.

- The strength of the car door is also increased (weight Reduction) from change of material from aluminium to Eglass epoxy.

- As the cost of the car door is increased by using the composite materials for the car door manufacturing and decrease the risk from the collisions.

- So we can conclude that using composite material E Glass is better.

\section{REFERENCES}

1. S. Acierno, R. Kaufmanc, F.P. Rivara, D.C. Grossman, and C. Mock, Vehicle Mismatch: Injury Patterns and Severity, Accid. Anal. Prev. 36 (2004), pp. 761-772.

2. M.D. Buhmann, Radial Basis Functions: Theory and Implementations, Cambridge University Press, New York,2003.

3. Gupta, I., \& Saxena, G. (2014). Structural Analysis of Rotor Disc of Disc Brake of BAJA SAE 2013 Car through Finite Element Analysis. International Journal of Automobile Engineering Research and Development (IJAUERD) Vol., 4, 1-10.

4. H. Fang, M. Rais-Rohani, Z. Liu, and M.F. Horstemeyer, A Comparative Study of Metamodeling Methods for Multiobjective Crashworthiness Optimization, Comput. Struct. 83 (25-26) (2005), pp. 2121-2136.

5. H. Fang, K. Solanki, and M.F. Horstemeyer, Numerical Simulations of Multiple Vehicle Crashes and Multidisciplinary Crashworthiness Optimization, Int. J. Crashworthiness 10 (2) (2005), pp. 161-171.

6. H. Fang and M.F. Horstemeyer, A Generic Optimizer Interface for Programming-Free Optimization Systems, Adv. Engg. Software 37 (6) (2006), pp. 360-369.

7. Behari, A. L. K. A. (2014). Professional Development of Elementary Teacher Educators: Issues and Challenges. Impact: International Journal of Research in Humanities, Arts and Literature, 43-44.

8. H. Fang and M.F. Horstemeyer, Global response approximation with radial basis functions, Engg. Optimiz. 38 (4)(2006), pp. 407-424.

9. Mr. Sandeep Bundele\&Dr.Rupa S. Bindu; “Automotive Door Design and Structural Optimization of Front Door for Commercial Vehicle with ULSAB Concept for Cost and Weight Reduction”; Global Journal of Researches in Engineering (Automotive Engineering); Volume 12 Issue 2 Version 1.0 (2012) 
10. O.M. Terciu, I. Curtu, C. Cerbu; "FEM Modeling of an Automotive Door Trim Panel made of Lignocelluloses Composites in Order to Determine the Stresses and Displacements in Case of a Door Slam Simulation”; The 4th International Conference of Advanced Composite Materials Engineering, COMAT 2012, Brasov, Romania, (2012)

11. Gupta, V., \& Saxena, G. Common Fixed Point theorem for Finite Number of Weakly Compatible Mappings in Quasi-Gauge Space.

12. Tan Wei, Wang Yan, Li Lingyang, Zhang Yu; "Design of the Vehicle Door Structure Based on Finite Element Method"; The 2nd International Conference on Computer Application and System Modeling; Wuhan, China (2012)

13. Royanian, S., \& Nozary, M. Elements of Hope and Life in the Poetry of Farrokhzad and Plath.

14. TawandaMushiri, and Charles Mbohwa; "Design of a Vehicle Door Structure Based on Finite Element Method"; 6th International Conference on Mechanical, Production \& Automobile Engineering (ICMPAE); Cape Town (South Africa); 2014.

15. Giancarlo Genta\&quot;Motor Vehicle Dynamics\&quot; Modeling and Simulation 